\title{
MATERIALIZED TRAUMA NARRATIVES OF BORDER CROSSINGS
}

\author{
Tuulikki Kurki \\ Professor of Cultural Studies \\ School of Humanities, University of Eastern Finland \\ tuulikki.kurki@uef.fi
}

\begin{abstract}
The purpose of this article is to discuss the applicability of the concept of materialized narrative in the analysis of border and mobility related experiences. In this article, the concept and its analytical potential are discussed in three examples that address difficult, even traumatic experiences related to various kinds of border crossings in Finnish and Estonian contexts. The concept of materialized narrative allows the conceptualization of border and mobility related traumas in supplementary and alternative ways. The materialized narrative is defined as a form of narrative and non-narrative knowledge that is linked with objects that people carry with them across various borders and their difficult experiences. The aim of the concept is to bring together the narrative and non-narrative knowledge of traumatic experiences that is embodied in a material object. The research thesis of the article is to examine how a materialized narrative can function as a trauma narrative. The article argues that materialized narratives can function as instruments for processing traumatic experiences related to border crossings, similarly to autobiographical trauma narratives that are regarded to be among the most central narrative forms analyzed in multidisciplinary trauma research. The research material includes interviews and artwork accomplished in the project "A Lost Mitten and Other Stories: Experiences of Borders, Mobilities, and New Neighbor Relations" (funded by the Kone Foundation).
\end{abstract}

Keywords: border, material culture, mobility, narrative, trauma

\section{INTRODUCTION}

Crossing the border between Finland and Estonia was very easy, but the change it required was always horribly difficult.

(Interview, February 15, 2019)

The purpose of this article is to discuss the applicability of the concept of materialized narrative (Kurki 2020a) in the analysis of border and mobility related 
experiences. The concept and its analytical potential are discussed in three examples that address difficult, even traumatic experiences related to various kinds of border crossings in Finnish and Estonian contexts. The article asks how materialized narrative can function as a form of trauma narrative in the context of geographical, cultural, and social border crossings.

\section{THEORETICAL AND METHODOLOGICAL FRAMEWORK}

In this article, materialized narrative is defined as an entanglement of verbal or visual narration and non-narrative knowledge, which is linked with objects (things, artefacts, macro artefacts) and various experiences related to border crossings. By default, a material object contains narrative and non-narrative information that can be, for example, verbal, visual, tactile, or performative, or some other kind of information that is mediated through the object's materiality and design, or through performance and interaction with the object (Kurki 2020a; Schiffer 1999). The non-narrative knowledge can also manifest itself in tacit or embodied knowledge of objects of the everyday environment, and in repetitive everyday routines with various objects (Kidron 2009: 6). Therefore, this article argues that the concept of materialized narrative has potential to bring together narrative and non-narrative information about difficult experiences related to border crossings. In addition to geographical and political border crossings, this article pays attention to cultural and social border crossings, such as those between health and sickness and the individual's integrity. Furthermore, the concept has potential to open multidimensional perspectives on understanding these experiences.

In the following, the article introduces the relevant discussions taking place at the intersections of the recent multidisciplinary trauma research, research on material culture, and multidisciplinary border studies, as well as the methodological framework. The analysis section examines two interviews and an artwork (a triptych installation) as examples of materialized narratives that address difficult experiences related to geographical, cultural, and social border crossings. These experiences include, for example, encountering aggressive behavior, feelings of exclusion and loss, and the violation of the borders of one's own bodily integrity. The analysis focuses on those strategies that the narrator applies when addressing the difficult experiences through the shape, materiality, texture, design, or color of the object, through interaction with the object (Schiffer 1999: 26), or through the collectively shared tacit meaning of the object. In addition, the analysis applies Michael Rothberg's (2009) concept of multidirectional memory in a situation where the analyzed objects are 
placed in a public exhibition. In the space of a public exhibition and in relation to each other, the objects make visible and audible different narratives of the border and mobility related experiences. The concluding chapter assesses the significance of the information about border and mobility related difficult and traumatic experiences that the materialized narrative can reveal. In addition, the potential that the concept of materialized narrative can have in multidisciplinary trauma research is also analyzed.

Theoretically, the article is placed at the intersection of multidisciplinary trauma research, research on material culture, and multidisciplinary research of borders and mobilities. The intersection forms a layered lens through which difficult experiences related to border crossings are addressed. The first theoretical lens is based on multidisciplinary trauma research. Trauma research became a prominent research trend in the humanities in the 1980s and 1990s. The early stages applied classical trauma models and theories formulated initially in early twentieth-century European psychology which stressed the difficulty or even sheer impossibility of verbalizing and communicating trauma, and the idea that the core of the trauma was unknown to the human consciousness (Caruth 2016 [1996]). Following this idea, Caruth (ibid.) argues that the representation or expression of trauma is always linked not only to what is known but also to what remains hidden in our actions and in our language. The idea of difficulty of expressing and verbalizing trauma has been widely covered in trauma research in the humanities (Stroinska \& Cecchetto \& Szymanski 2014).

Today, the theoretical models in trauma research in the humanities have widened from trauma psychology to the social and political aspects of trauma (Kaplan 2005: 25). These models have also questioned the universality of the definition of trauma, as early definitions were largely based on the experiences of white middle-class Europeans. Michelle Balaev (2014) argues that contemporary trauma research applies several trauma models simultaneously, instead of the single classical, psychological model. To describe the various and simultaneous contemporary theoretical approaches, Balaev (2014: 3-4) introduced the concept of a pluralistic trauma model. According to Balaev, the pluralistic trauma model can combine different trauma theories, and therefore offer different analytical lenses through which to study trauma. In addition, Balaev argues that the pluralistic trauma model shifts the focus away from the impossibility of representing trauma to the uniqueness of trauma. This article also combines several theoretical underpinnings originating from different research areas to provide alternative analytical lenses on border and mobility related difficult and traumatic experiences.

Yet, another growing dimension in trauma research, especially in Holocaust studies, is that of memory studies (Hirsch 2008: 105). Some of the trends in the 
memory studies stress the relationality and negotiability of different memories. For example, the concept of multidirectional memory introduced by Michael Rothberg (2009) stresses the simultaneity, relationality, and negotiability of different memories in the public space. Questions of the politics of memory and memory activism have also become a prominent theme in memory studies (Roseman 2016). The purpose of memory activism is to express traumatic histories of formerly oppressed and silenced groups, or histories that have only partially been presented before (ibid.). Utilizing the idea of memory activism, this article attempts to highlight such difficult experiences related to border crossings that may remain largely hidden and invisible as they take place in seemingly ordinary everyday situations.

The second theoretical lens of the article is based on material culture research. The so-called material turn occurred in the humanities in the $1990 \mathrm{~s}$, and made (again) everyday material culture a prominent research object with an aim of formulating the relationship between material and non-material culture in novel ways (Dolphijn \& Tuin 2012: 85-86). Typically, modernist thought examined material and non-material culture as separate spheres. The material turn and the so-called new materialism aimed at examining them as intertwined "in their entanglement" (Dolphijn \& Tuin 2012: 91). Following this idea, this article examines the material objects and experiences related to border crossings through their entangled narrative and non-narrative articulations.

Utilizing material culture in trauma research is not new. Research has been done on private everyday material objects, as well as public memorials, memorial sites, and statues (Parkin 1999). For example, Kidron (2009) examines a spoon that originates from a German concentration camp in the 1940s. The spoon has accompanied a Holocaust survivor throughout the survivor's life. Kidron (ibid.) examines the spoon as an embodiment of the survivor's family's non-verbal, collective, and traumatic memory. The human body has also been examined as an embodiment of traumas, and as an instrument for processing traumatic experiences (Formenti \& West \& Horsdal 2014). For example, jewelry and tattoos attached to the human body, which have historically had negative cultural connotations (Ruotsalainen 2015), have been examined as instruments for processing trauma and healing, after difficult and traumatic experiences have strongly affected the identity narrative of an individual (Alter-Muri 2019; Maxwell \& Thomas \& Thomas 2020).

Some research has been implemented on traumatic experiences in relation to material objects and various borders, border crossings, and mobility (Nguyen 2016; De León 2013; Povrzanović Frykman \& Humbracht 2013; Woodward 2001; Drechsel 2010; Dudley 2010). This article builds on the theoretical formulations brought forward by De León (2013) and Dudley (2010; 2011). De León examines 
the material objects illegal border crossers from Mexico to the United States leave behind in the border area. Through these objects, De León analyzes the complex processes of migration, and the larger economic structures that affect migration. In addition, De León analyzes the material objects as material fingerprints, and as signs of affliction resulting from the suffering that the illegal border crossers experience in the border zone. Dudley $(2010 ; 2011)$ takes a different approach and examines the role of material culture, the production and consumption of food, textiles, and their contribution to feeling at home among displaced people in exile.

Building on these theoretical underpinnings, this article aims at examining the possibility of a materialized narrative functioning as a trauma narrative. A significant part of trauma research in literature studies and the humanities (for example, in folklore studies) has focused on autobiographical narratives (Jensen 2019). An essential element of processing trauma is the person's ability to re-form and re-narrate their life narrative after the traumatic experience. The autobiographical narrative provides questions that can be used as a means of processing the trauma, and so rebuilds one's life narrative (Jensen 2019). For this reason, the life narrative has remained one of the central objects of research in trauma research. However, Jensen (ibid.) argues that other narrative forms, such as various textual, visual, and performative narratives, or memorials and statues, similar to an autobiographical narrative, can also address key questions and apply rhetorical devices for processing trauma. Therefore, according to Jensen (ibid.), other narrative forms and genres can form important research objects in trauma research in the humanities. For example, the other narrative forms may examine the changing relationship between the narrator and past events, and so redefine the narrator's sense of self. Jensen (ibid.) argues that a performance or a statue, for example, can form a public space where such trauma related narratives can be made audible and visible, and can be shared. Through a performance, a history of a certain group can be articulated and made visible, although this would involve rhetorically distanced witnessing (ibid.). According to Jensen, the processing of trauma compares to a narrative negotiation about past occurrences and their significance.

In this article, trauma refers to two different situations. First, it refers to a so-called trauma event; that is, a single, sudden, large-scale, and traumatizing event, such as experiencing or witnessing violence or an industrial or natural catastrophe. The experience of trauma is often belated and uncontrolled (Caruth 2016 [1996]), while the trauma event itself is usually highly visible and recognized by large groups of people. In addition to trauma events, in this article trauma also refers to rather ordinary everyday encounters that may be harmful and traumatizing to certain groups of people. In these cases, the person 
may face, for example, micro-aggressive behavior, invalidation, and exclusion, which cause severe feelings of anxiety, depression, and non-belonging (Tanttu \& Kurki forthcoming; Facemire 2018; Sue et al. 2007). The traumatic nature of these seemingly ordinary everyday encounters may remain invisible and hidden from the society at large. These types of traumatic experiences have been called insidious trauma (Brown 1991: 128) and are seen as a second type of trauma (see Traumaterapiakeskus), resembling the concept of minority stress (Meyer 1995). When continuing for an extended period, insidious trauma may cause similar symptoms as seen with a singular, large scale trauma event (Facemire 2018: 10). In this article, insidious trauma refers to the crossing of various cultural and social borders in everyday encounters; however, the consequences of these border crossings are potentially harmful. These cumulatively traumatizing border crossings may occur consistently without even being noticed. Therefore, it is important to become aware of the potential for seemingly everyday situations to be traumatizing.

When analyzing the examples in this article, the methodological guideline is based on the idea of a physical trace as defined in archeology. In archeological inference, a physical trace is understood as evidence from past occurrences that is no longer visible or accessible directly (Schiffer 1999: 52-55). The idea of a trace (or a clue) has been applied widely as a methodological metaphor in the interpretation of both texts and visual materials (Ricoeur 1988: 119-120; Ginzburg 1992: 96-103; Jones 2007: 19-21). Thus, a trace can first appear as a seemingly irrelevant detail in a text or image, but through interpretation it is thought to provide access to information about the past that has remained previously unarticulated. In this article, a material object is seen as a trace of non-narrative knowledge about border related experiences that may be challenging to verbalize, or that may remain unnoticed in society at large.

\section{RESEARCH MATERIAL AND METHOD}

To discuss the analytical potentiality of the concept of materialized narrative, the article analyzes three examples of the research material gathered and prepared within the research project "A Lost Mitten and Other Stories" in 2018-2020. The project was implemented at the Karelian Institute, University of Eastern Finland. The four main research interest areas in the project are borders, mobile identities, dialogue, and new neighbor relations, which were examined using traditional ethnographic interview methods as well as through artistic and applied arts-based research methods (McNiff 1998; Leavy 2015). ${ }^{1}$ The traditional ethnographic research methods and artistic working methods 
were applied dialogically throughout the project: starting from gathering the research material, through the analysis, and finally publishing research findings to wider audiences outside academia.

The interviews focused on objects that accompany people across various (for example, geographical, cultural, linguistic, or social) borders, or such borders that people regarded as important in their lives. This focus was formulated as the main theme in the call for interviewees. The interviews (54 in total) were conducted by four researchers working within the project during 2018-2020 (see the list of references for more details). The interviews followed a thematized list of questions that were arranged according to the main four research interests of the project. The aim was not to address each question of the list in each interview, but rather to allow each narrator to focus on those themes and questions they regarded as most relevant. The two interviews and the artwork selected for this article highlight aptly the different types of difficult experiences related to mobility and border crossings in the Finnish and Estonian contexts.

In addition to the interviews, creative workshops were arranged to gather visual research material addressing the four theme areas. Creative and artistic methods provided additional instruments for processing and analyzing research material, and later in publishing the research results in unconventional forms. In addition to the artist working in the project, researchers addressed the research themes through artistic and creative working, such as handicrafts, animations, and cartoons (Tanttu 2020; Kurki 2020b; Korolainen 2020). Furthermore, in co-operation with the North Karelian Museum Hilma in Joensuu (Finland), the project implemented an interactive exhibition about the research themes, border crossing objects, and the narratives linked to these objects. The exhibition also included artistic and creative outputs by the project group which addressed the central themes of the project in their works. The exhibition was also launched in an open-access, interactive 360 panorama form. ${ }^{2}$

In the following text, two specific interviews are analyzed, one about a camera, and the other about a crocheted pincushion. In addition, a triptych artwork entitled "Pistoksissa" (Injected), which was prepared by artist Päivi Saarelma and based on an informant's story, is analyzed. The interviewees and the informant were between 28 and 88 years of age, and were residing in eastern Finland where the project territorially focused. The selected examples of the camera, pincushion, and artwork highlight the wide range of border crossing experiences contained in the research material. The artwork differs in its form from everyday objects; however, it is prepared using medical objects that are significant to the informant and reflect the informant's difficult experiences at societal and cultural border crossings. The artwork further functions as an example of a situation where everyday speech and everyday forms of communication are 
not able to address the traumatic experience, and the trauma must thus be addressed through artistic expression. Similar to the camera and the pincushion, the artwork functions as a materialized narrative that allows the border related difficult experience to become visible, tangible, and audible through abstraction.

\section{EVERYDAY OBJECTS: UNCANNY INSTRUMENTS FOR PROCESSING DIFFICULT EXPERIENCES}

This section analyzes three examples of situations in which an object functions as an instrument for processing difficult experiences related to border crossings. The negotiation takes place through the object's visuality, materiality, or through interaction with the object.

\section{Camera and negotiation of difficult border crossing}

In the first narrative, a camera performs as an instrument for examining and negotiating border crossing and the difficult experiences that are related to it. The narrator was a young girl, under 10 years old, when she and her Ingrian Finnish $^{3}$ grandmother moved from Estonia to Finland after the collapse of the Soviet Union in the 1990s. The narrator's parents remained in Estonia and therefore her family was split across the Estonian-Finnish national border. As a result, in her childhood and adolescence, the narrator traveled regularly to Estonia to see her family there.

Crossing the Estonian-Finnish national border was easy during these trips, however there were very difficult personal experiences related to the border crossings. Each time, when traveling back to Finland after visiting Estonia, the narrator experienced Finland as a strange country, where she could not fit in. Crossing the national border between Estonia and Finland caused the narrator's identity to be questioned, as well as the ways how she should behave in each country. In Estonia, the narrator felt she could freely be herself, while in Finland, the narrator thought that she was seen primarily and one-dimensionally as a migrant, which hid her true identity. In the role of a migrant, her belonging to Finland was frequently questioned and she felt like being somehow wrong and an outsider. Moving to Finland also meant facing an invisible border that separated 'we' from the 'other' in Finnish society, and facing that border was challenging and even traumatizing for the narrator. She became a victim of vicious bullying at school because of her different background. The narrator thought that because of the bullying, she had to hide the Estonian side of her 
identity from others, and her difference was not supposed to be allowed to show. Thus, as a consequence of the bullying, it took a long time for the narrator to accept her Estonian background (Interview, February 15, 2019).

Her grandmother gave the narrator a Minolta $35 \mathrm{~mm}$ film camera to take photographs (Fig. 1), which became a crucial instrument with which she could document and process the border crossings between Estonia and Finland. During the several years when the narrator travelled regularly between Estonia and Finland, she avidly photographed her former home and its material surroundings in Estonia, where she could no longer live but only visit for short periods of time. She also documented the gradual and rapid changes that occurred there. Later in Finland, she started to photograph her new living environment and its features, such as a kiosk nearby her home. But only rarely did she photograph people.

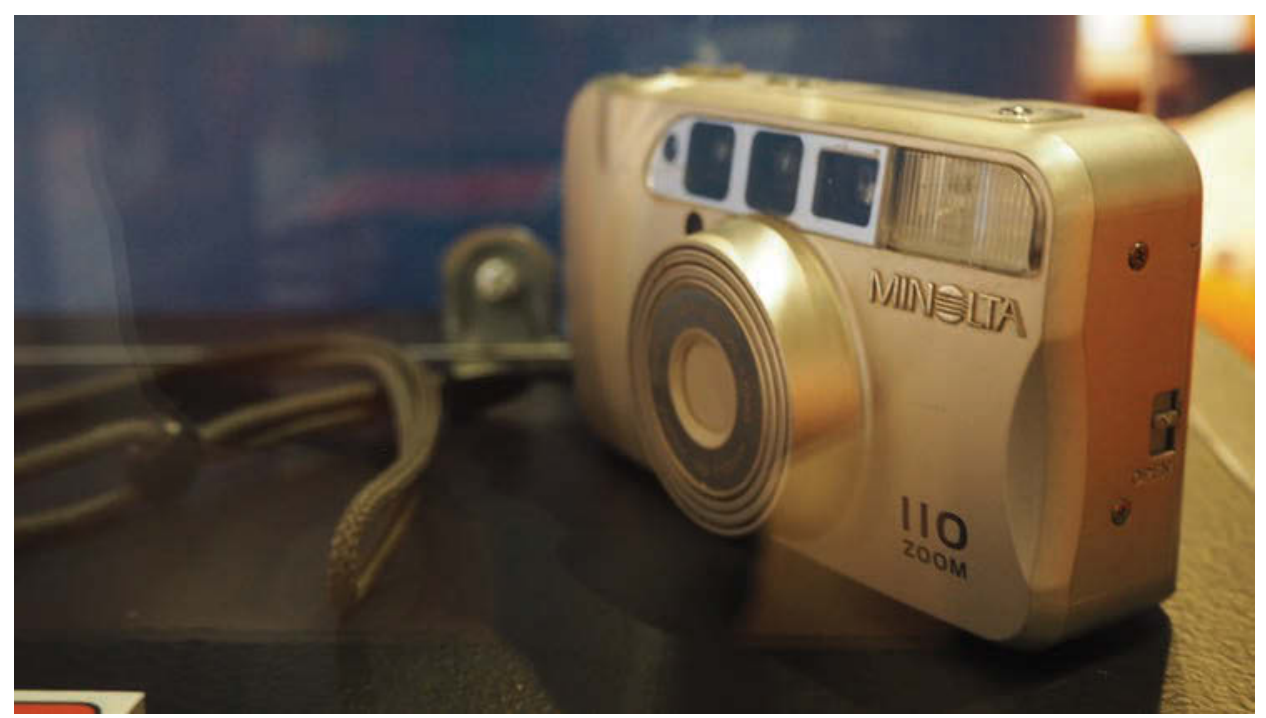

Figure 1. The Minolta $35 \mathrm{~mm}$ camera that the narrator used for photographing places in Estonia and Finland. Photograph by Tuulikki Kurki, February 15, 2019.

The act of photographing can be understood as a form of processing and negotiating border crossings and the difficult experiences that are related to the crossings. In the act of photographing, the narrator/photographer looks at the object through the viewfinder, frames the scene, and takes the photograph. The negotiation takes place through her changing presence in the photographed 
locations, and through her changing perspective on the photographed objects that she regards as meaningful. Furthermore, looking at the photographs repeatedly over time can be understood as a form of negotiation, because the viewer's interpretation of the photographed objects changes. In both these negotiations of photographing and viewing, the narrator's relationship to the past and present, to her former home country of Estonia and her new home country of Finland, and her relationship to places, people, languages, and cultures is re-created.

I have photographed the village or things like that, to see whether they have changed or remained the same. For example, I took pictures of a ditch, and a couple of years later I went back to take photos again. So, I can see if the ditch has deepened, if the water level is higher or lower, or if it has changed at all. (Interview, February 15, 2019) ${ }^{4}$

In the example, the narrator explains how she has photographed her former homestead, home village and its surroundings in Estonia. To observe subtle changes in the material environment, the narrator took photographs of specific targets over several years. In this way, she followed the growth of trees, the deepening or shallowing of water in ditches, and the changes that people had made to the environment. The changes in the material environment she observed through photographing reflect the flow of time for her, and also her changing relationship to the environment. Her perspective becomes gradually more distanced as she spends less and less time in Estonia. Furthermore, her connection to her former home is maintained mainly through the selected material objects that are documented in the photographs. Some of the more radical changes in the environment were stressful to her, because they deeply threatened her sense of belonging in Estonia and destroyed the material embodiments of her dear memories of life there. One of these changes was the cutting down of a spruce tree that her mother had planted in the home yard decades ago.

I became so angry because my mother's spruce had been cut down. For me it was my mother's spruce, and you were not supposed to cut it down. My mother said that it had grown askew because of the lack of sunlight, and the lower branches were already decaying, and things like that. But for me it was still my mother's spruce and you were not supposed to cut it down. When the tree had been cut down and it was not there anymore when I arrived there, I was bitter for three days at least. (Interview, February 15, 2019)

For the narrator, the tree had always been 'her mother's spruce', and therefore untouchable, although her mother herself had spoken about the necessity of 
cutting it down. Cutting down the spruce threatened the narrator's memory of her mother and their family's shared time in Estonia, which was materialized in the tree. The narrator refused to accept the erasure of the material embodiment of a dear memory of her mother and her childhood, as well as her connection to the place. Another stressful change in the material environment was the renovation of her grandfather's traditional homestead that had been also the narrator's home in her childhood in Estonia.

My grandfather's house, I loved it. ... Nowadays, my uncle lives in grandfather's house. ... When my uncle settled in the house, he demolished the other side of the house and turned it into a motorcycle garage. ... I felt so sad about it. Grandfather would have never accepted the demolition. (Interview, February 15, 2019)

The narrator felt that the renovation destroyed the grandfather's house that she had loved so much, and thus the renovation threatened her dear memory of that place and her grandfather. Furthermore, the narrator felt that renovating grandfather's house in such a radical way was an act that went against her grandfather's will, and also against herself because her relationship with her grandfather had been close and she felt that she was the only one alive who really understood the grandfather. Through photographing the changing environment, buildings and locations, the narrator addresses the irreversible changes and loss of home and the significant people in her life. In addition, the act of photographing addresses her own distancing from her Estonian roots. When narrating the material changes that have taken place, the narrator feels frustrated and angry. However, at the same time, change and loss become parts of her life story and her identity narrative.

Through photographing, the materialized narrative about border crossing experiences became linked with clearly defined material objects in Estonia, such as bushes, trees, houses, ditches, and other details of significant places. The camera also functions as an instrument of narration. The narrator's point of view and her bodily relationship to place and time (cf. Jensen 2019), to her past life and former home region, and also its materiality have changed over the years. The difficult experiences of loss and irreversible change are attached to materialized details in the surroundings that the narrator attempts to document as extensively as possible. In 2019 , when the interview was conducted, the narrator explained how she tried to incorporate aesthetic qualities in the photographs, instead of focusing only on documenting details as much as possible. This provides a clue that the narrator's view of their former home place and the events has changed. She processes her relationship with her former home region 
by adopting a distancing view, like any aestheticization as an artistic means of expression serves to distance the photographing subject from the object.

Although her Minolta $35 \mathrm{~mm}$ film camera no longer works, the narrator still carries it with her. It is now a keepsake from her grandmother and an uncanny reminder of her past life when, as a child, she grew up between the two countries, their cultures and languages. The memories of a past life, experiences of border crossing, and processing these difficult experiences are also linked with the materiality of the outdated and broken camera that is no longer part of the functioning present. However, the narrator continues to photograph her present life with her new digital camera. Purchasing her own camera reflects the independent life that she has established in Finland, but it also signals a break in the materialized narrative linked to her childhood and her constant border crossings.

\section{A crocheted narrative of war and loss}

An object can also function as an instrument for processing a person's or family's lost history. In the research material of the project "A Lost Mitten and Other Stories", a bust statue of Beethoven from the 1980s, the robbed and lost silver and gold treasures of a family in the 1980s, and a self-made pincushion from the 1930s are examples of objects that function in this way (interviews on December 20, 2018; April 27, 2019; June 19, 2019). The following example analyzes a self-made pincushion (Fig. 2) as a materialized narrative. Here crochet with its materials and colors functions as an instrument for processing difficult experiences of war and the loss of a home and family members.

When the so-called Winter War broke out between Finland and the Soviet Union on November 30, 1939, the narrator was nine years old. She lived in eastern Finland, close to the border of the Soviet Union. When the war broke out, her family as well as other evacuees had to quickly flee from their homes. Everyone was allowed to take only a few items with them because there was not much space in the horse-drawn sleighs and trains that took the evacuees away from the border area. The narrator remembers that it was very difficult to decide what to take with her and what to leave behind. Everyone knew that what was left behind would probably never be retrieved. The narrator decided to quickly crochet a small, light pincushion and stuff it with small cloth patches that she found in her home. She then packed the pincushion in her small rucksack. Now, 80 years after the evacuation, the narrator still has the pincushion with her, and it has traveled with her throughout her life. 


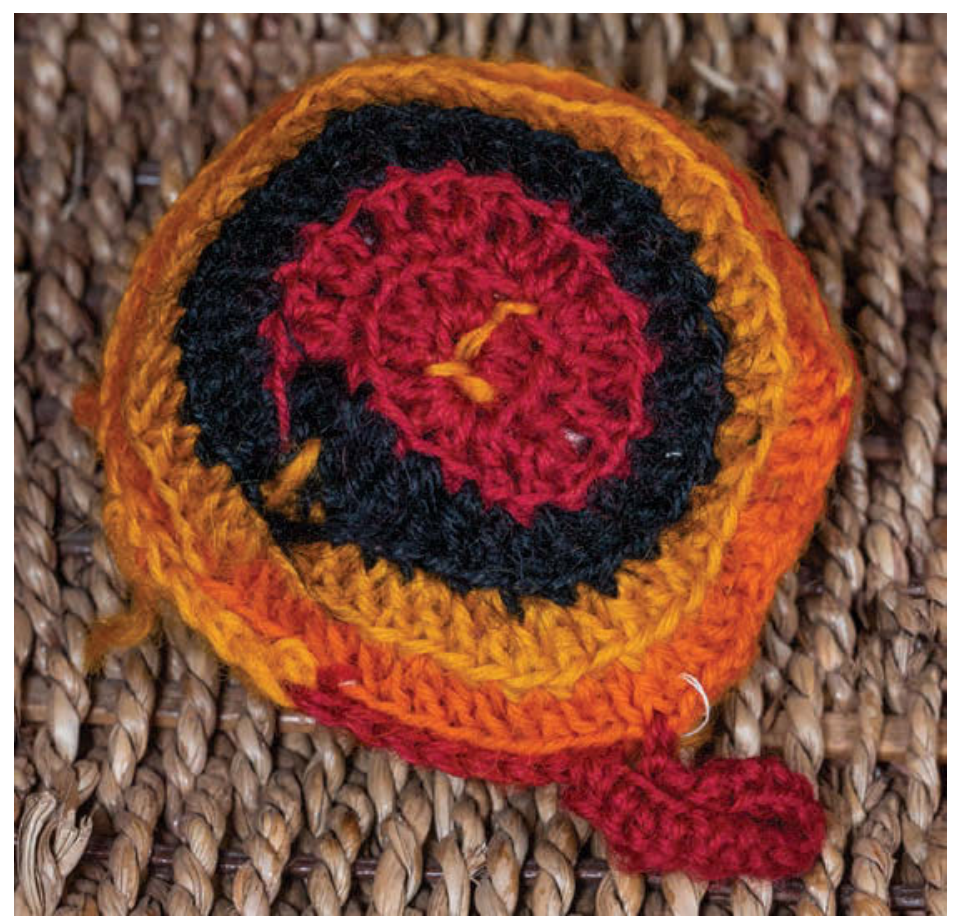

Figure 2. The pincushion that the narrator crocheted at the dawn of the war. Photograph by Rami Saarikorpi, July 23, 2020.

The evacuation was a terrifying event. The family had to leave their home quickly at night. It was dark outside, and the temperature was freezing. The family planned to ride in a horse-drawn sleigh to a civil guard house where evacuees were gathered before sending them inland by train. However, the bridge across the river leading to the civil guard house had been exploded, and the family had to change their plans rapidly. They managed to drive their sleigh to another village in the middle of the night, and they were able to recover there for a few hours before continuing their journey the following morning. On the escape route, their sleigh fell over several times because of the icy condition of the road. Each time, the Finnish soldiers who were marching to the frontline turned the sleigh back on its runners so that they could continue their escape. Being suddenly drawn into the middle of the war and a hurried evacuation was an overwhelming experience for a child. The narrator describes the situation as being chaotic and horrible. When the narrator was able to get onto the evacuation train, she felt as if another life began for her. In the crowded train car, she watched all the different people coming from different places and listened to all 
the frantic noises. She said she thought that she was in a theater, and obviously she felt distanced from the very disturbing events (interview, June 19, 2019).

Later in her life, the remaining pincushion became an embodiment of the evacuation and the war, as well as their tragic consequences.

This [pincushion] is like a threshold to the past life. These colors remind me of that time we lived in. I do not understand what attracts me here... however, it is shocking, here around everything is yellow and bright, in the middle there is red, like it would be a heart, and around it is a black circle. Well, this describes our ... well I did not think about it then, but the life story just appeared here spontaneously. There have been sorrow and joy and sunny days, but they all are there in the bottom of the heart. (Interview, June 19, 2019)

When crocheting the pincushion as a child, the narrator created a material embodiment of the painful and traumatizing event of war. In the example, the narrator's past experiences are materialized in the colors of the pincushion. The crocheted wool threads of red, black, yellow, and orange remind her of the time of the evacuation, and furthermore, of her entire life since that time. However, the narrator does not explain choosing the colors of the threads purposefully as a child. To make the pincushion, she had quickly collected some materials that she found in her home. Now, as an elderly person, she has found personal significance in each color in the pincushion. She explains that the red center of the cushion reminds her of the heart that holds all her important memories and her life itself. The black circling around the heart reminds her of extremely difficult times and the sorrows in her life: leaving and losing the childhood home, constant homesickness, war, and losing her father and two brothers in the war. The yellow and orange colors forming the outer edge of the cushion remind the narrator of the happier times in her childhood before the war, and also after establishing her life again after the war. Looking at and interacting with the pincushion in the research interview in 2019 activated her memories of the past life. Although the pincushion has not been an object of active remembrance in the narrator's everyday life, it has traveled with her and still continues to fascinate her.

In 2019, on the eve of the research interview, the narrator and her daughter decided to open the pincushion to see what it was stuffed with. They found patches of cloths inside, and the narrator recognized patches of her own velvet dress that she had been wearing as a child.

This is the best of all patches, a patch of memories, and here [inside of the pincushion] was a piece of my first velvet dress. I remember it vividly 
when I got it; it was a Christmas celebration in the school, and I wantedbecause I was spoiled a little, I was acting up - the dress to be made of velvet. And I got it, it was reddish, and yes, it was here. ... it was the best, the memory of the velvet dress patch. (Interview, June 19, 2019)

By opening the pincushion, the narrator and her daughter were undoing the crocheted embodiment of the past events and dismantling the materialized memories. They found out that the pincushion included randomly selected small patches of clothes from the narrator's childhood home. One of the pieces was from the narrator's own velvet dress that she had worn as a child in elementary school. The piece reminded her of herself as a child who liked pretty things, and of the happier times before the war. By dismantling the pincushion, the narrator was peeking at the heart of her memories, herself, and her expected life-narrative that was interrupted by the war. These had been hidden from view for decades but were now revealed in the form of colorful patches. Together with her daughter, it became possible for her to reassess the significance of the materialized embodiment of her difficult memories. In their eyes, the value of the pincushion increased, after they had had a chance to share together the narratives of the past.

\section{The triptych "Injected"}

The triptych "Injected" by the artist Päivi Saarelma, working in the project "A Lost Mitten and Other Stories", is an example of a different kind of, but nevertheless potentially traumatizing border crossing. The triptych shows the invisible, exclusionary borders in the Finnish society that demarcate and exclude those who do not fit with the ideas of the majority. As a result, the excluded individuals and groups may encounter an insidious trauma, when their experiences of exclusion and rejection are persistent.

The triptych includes three visual elements: a dress installation, an ampoule installation, and a syringe installation (Fig. 3). As a fourth element, it includes an audio narrative. The materials of the triptych belong to an informant who has to self-administer medicine through injections and infusions regularly, in order to be able to live her daily life and maintain her daily functionality. The dress installation is comprised of used butterfly needles with thin plastic tubes and the plastic cover bags of syringes. The needles and tubes form the bodice of the dress, and the plastic cover bags form its skirt. The ampoule installation includes 450 used $20 \mathrm{ml}$ glass ampoules. The ampoules are arranged in a white wooden square-shaped frame, and a small led light is installed inside each ampoule. The syringe installation includes 120 used plastic syringes placed 
in a row and attached to a wall. The plunger of each syringe is adjusted in a way that the plungers form a shape of an arrowhead on the wall. The audio narrative that is also part of the installation allows the listener to hear the informant's account of her experiences of injecting the medicine and being the object of various medical treatments.

This dress is made of butterfly needles and the plastic covers of syringes.

I have used these needles and syringes to measure medicine for myself that is needed in the treatment of an illness. I have injected all the needles through my own skin.

The pain does not show outwards.

Many illnesses, and the suffering that comes along with them, do not show outwards although they swallow your strength and sometimes even your zest for life.

The insides of my elbows are scarred, and they can give a clue as to how many blood samples have been taken from me. A thousand, even more.

When you are ill, you cannot protect your body or control the boundaries around it. You are forced to allow various people to interfere with you, without asking permission.

I have learned to protect myself by singing when it hurts terribly badly. Or humming. Purring like a cat. These needles, syringes, and ampoules make the pain visible.

(Triptych "Pistoksissa" ("Injected"))

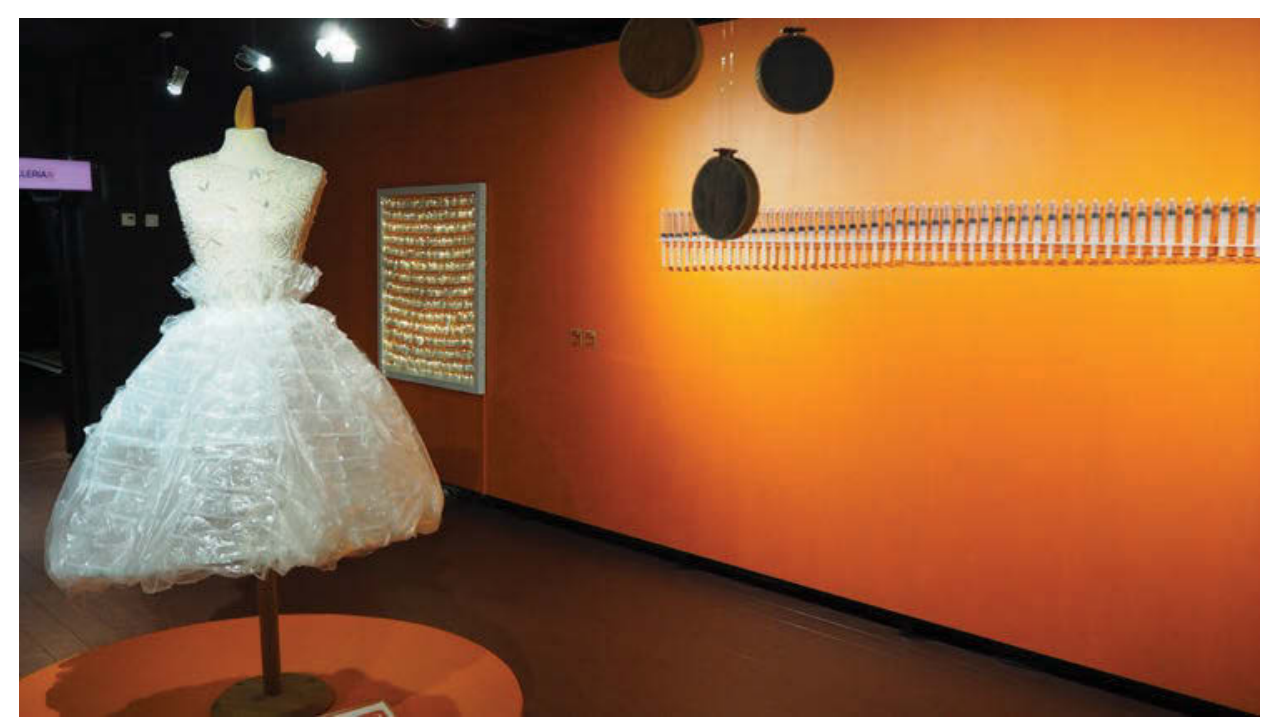

Figure 3. The triptych "Injected” by Päivi Saarelma. Photograph by Tuulikki Kurki, July 16, 2020. 
The triptych addresses the question of crossing the social and cultural borders between 'health' and 'sickness', as well as 'majority' and 'minority'. It also addresses the question of crossing a person's personal bodily borders and interfering with their privacy and agency, and the person's struggle to protect their borders, which turns out to be impossible when ill. The insidious trauma that is related to these border crossings concerns the micro-aggressive attitudes that the majority may direct towards people with chronic illnesses and disabilities. These microaggressions become visible in everyday discourses, for example in the media that stresses healthy, capable, and strong bodies, as well as performance-oriented values which are seen as the norm. The narrator describes her condition as invisible to others, and therefore she does not experience being part of the norm. Material signs of this difference are the acts of self-administering medicine with infusions and injection needles, and the scars in the insides of her elbows that somewhat compare to jewelry and tattoos as embodiments of identity, memory, and experience.

The triptych and the narrator's account can also be understood as a commentary on the terms that the functioning society is built on, as they assume that its members are healthy and fully functioning citizens. The narrator describes how the illness and suffering swallow her strength and zest for life and leave her with the experience of not fulfilling the duties of a fully functioning citizen. Because of this, the narrator feels that people with chronic illnesses and disabilities are automatically excluded from the "we" represented and constructed in mainstream discourses. The physical symptoms, pain and treatment remind the narrator of these exclusionary practices on a daily basis. This leads to experiences of being rejected, marginalized, and ignored, as well as of becoming invisible in the mainstream society. When these experiences continue a longer period of time, they may lead to experiences of prolonged stress and the development of insidious trauma. The materialized narrative embedded in the installation makes these difficult experiences visible and audible.

One of the key elements in the triptych is the question of pain that is not easily seen by others. The pain simultaneously signifies the distinction between the social and cultural categories of health and sickness. The pain that the informant has carried with her throughout her life is highlighted with the uncanny combination of materials used in the installation. From a distance, the dress appears to be glamorous and chic, and a shimmering design garment due to its transparent, plastic materials. The glass ampoules and plastic syringes also raise immediate curiosity, and expectations of beauty and attractiveness due to their shiny character. Thus, the triptych plays with the cultural signs of beauty, elegance, and glamour. However, a closer look at the triptych reveals a combination of beauty and pain, as well as delicateness and ruthlessness that 
is denoted by the fragile plastic materials of the dress, and the sharp needles piercing the body of the mannequin mimicking the violent act of injection. The materials of the triptych make the pain and suffering evident, but also make the repetitive inference of bodily borders visible. As an artwork, the triptych brings the individual painful experience to a more general level, so as to represent the experiences of people that are excluded and rejected due to their difference from the majority.

\section{Museum exhibition as a space of multidirectional memory}

The project "A Lost Mitten and Other Stories" created an interactive exhibition in co-operation with the North-Karelian Museum Hilma in Joensuu (Finland) in the spring and summer of 2020. The exhibition was built around approximately 80 objects that had accompanied the interviewed people and the informants across various geographical, cultural, social, and linguistic borders, and their personal narratives were attached to these objects. In the space of the museum exhibition, narratives relating to different geographical, cultural, and social contexts, and time eras, as well as various personal experiences were set in relation to each other, and thus became audible and visible in relation to each other. The exhibition also allowed the visitor to see the connections between individual, separate, and often difficult experiences related to border crossings.

Gaining more complete knowledge and understanding about the experiences related to border crossings requires merging the narrative and non-narrative information embodied in the exhibited objects. In an exhibition, interaction with objects and a close reading of art (such as installations and drawings) allows one to immerse oneself in other people's narratives and non-narrative expressions - in other words, materialized narratives may allow understanding to rise by way of empathy and experience-based understanding (see Bonansinga 2014) as well as through multi-sensory levels (De León 2013: 330). In the exhibition, the visitor could empathize, for example, with the experience of leaving home suddenly but permanently, negotiating one's belonging to a new home country, with feelings of exclusion, and living between two countries and cultures. In one of the interactive tasks, the visitor found a letter in an old rucksack. The letter described an evacuation story of a little girl and prompted the visitor to create a list of items that they would pack in a small rucksack with them in the case of evacuation. The visitor could also empathize with the experience of losing something dear by imagining the lost objects in an empty showcase, and simultaneously reading the narrative about the stolen and inevitably lost family treasures and what the lost objects meant for the narrator. In these 
examples, the object also functions as a trace of the past events and the narrator's personal experiences of those events. The interactive realization of the exhibition can be further supported by Arnold-de Simine's (2013: 10) argument that material objects in a museum exhibition "function as anchors and proofs of historical events", because they "draw visitors into an imaginative encounter with the past". Furthermore, Arnold-de Simine argues (ibid.) that the objects help visitors "to gain access to a time they have not experienced themselves by identifying with individuals and their personal stories", and this often takes place through reliving the past "through the eyes of individuals and their personal memories", and by "stepping into the shoes" of other people (ibid.).

The materialized narratives have also the potential to reveal and make tangible such experiences related to border crossings that would otherwise remain unnoticed by the majority. Materialized narratives may also help in making difficult experiences tangible, visible or audible in cases when narrating these experiences is challenging (see Jäntti \& Loisa 2018). However, representing traumatic experiences in an exhibition has an ethical dimension and imperative to remember (Arnold-de Simine 2013: 3). Arnold-de Simine argues (ibid.) that "mere knowledge about the past does not suffice to prevent the perpetuation of violent and traumatic histories. The ethical imperative to remember is taken to its literal extreme: visitors are asked to identify with other people's pain, adopt their memories, empathize with their suffering, reenact and work through their traumas." Therefore, empathizing and identifying with other people's difficult experiences to gain a more thorough understanding was also one of the goals of the exhibition "A Lost Mitten and Other Stories".

\section{CONCLUSIONS}

The analyzed examples show three different materialized narratives that address and negotiate the relationship between the narrator and their difficult experiences relating to various kinds of border crossings. Based on the analyzed examples, this article argues that the concept of materialized narrative has potential in the field of multidisciplinary trauma research and could function as a form of trauma narrative on individual and collective levels. Furthermore, it has potential as a research instrument in trauma research.

On an individual level, the potentiality of the concept of materialized narrative is highlighted by the fact that it is often challenging to verbalize or communicate difficult and traumatic experiences (Caruth 2016 [1996]). This article argues that materialized narrative could provide an alternative instrument for processing and negotiating border and mobility related difficult and 
traumatic experiences through the individual's interaction with the object, by doing, touching, and viewing. Interacting with the object may help the individual to address such questions that are elementary in re-establishing and re-narrating an individual's life story after a difficult and traumatic experience (cf. Jensen 2019). Examples of re-narrating the life-story through interaction with an object were especially well shown in the examples of a camera and a crocheted pincushion.

On the societal level, the potentiality of the concept of materialized narrative is highlighted when examining so-called insidious traumas, where difficult and traumatic experiences take place in everyday contexts across various kinds of visible and invisible borders. However, the traumatizing character of these seemingly ordinary border crossings may remain invisible in a society and culture at large because they are not based on a single, large-scale catastrophic event that is recognized by large groups of people. Through materialized narratives, these otherwise invisible traumas can become visible and be addressed individually or by larger audiences. This was shown especially in the examples of the camera and the triptych "Injected". When an object and the materialized trauma narrative are brought into a public space in an exhibition, artwork, or installation, the past occurrences become objects of public and multi-voiced discussion. In public exhibitions, materialized trauma narratives also have the potential to become parts of the acknowledged collective memory.

It may be possible to bring difficult experiences into the public space and process them through material forms and in various non-verbal forms. For example, an artwork or a publicly displayed everyday object can function as an instrument for asking "disturbing questions" and raising "unexpected claims" (Oliveri 2016: 160), and in this way enable understanding to develop beyond stereotyped expectations and self-evident assumptions. By asking disturbing questions, the objects may also increase awareness about various cultural and societal borders that may be partially invisible, but nevertheless harmful and traumatizing for many.

From a research point of view, a materialized narrative could form a valuable methodological instrument for conducting interviews and gaining information about difficult experiences. In the context of an interview, interviewees may approach difficult themes more easily through narratives about an object than through directly addressing their own personal experiences and feelings. Also, the creative working methods and artworks realized, for example, in cooperation between an informant and an artist may allow narrative and non-narrative articulations of difficult experiences to emerge and be expressed in new ways. 


\section{ACKNOWLEDGEMENTS}

This article was written within the project "A Lost Mitten and Other Stories: Experiences of Borders, Mobilities, and New Neighbor Relations", funded by the Kone Foundation.

\section{NOTES}

1 In addition to interviews, the research material included written texts, questionnaires, and works realized through various visual creative methods in creative workshops in 2018-2019. These materials are significantly fewer in number than the interviews because the majority of the informants wished to participate as interviewees.

2 The exhibition Kadonnut kinnas ja muita tarinoita (A Lost Mitten and Other Stories) was open from February 6 to March 17, 2020, and again from June 1 to August 2, 2020. The exhibition was closed from March 18 to May 31 because of the Covid-19 pandemic. Based on the exhibition, the project launched a virtual $360^{\circ}$ exhibition that is available at https://360panorama.fi/360KadonnutKinnas/.

${ }^{3}$ Ingrian Finns received the right to return to Finland in the early 1990s. The return migration meant that Finns and people with Finnish roots (like Ingrian Finns), who lived abroad, could move to Finland. The return migration was implemented from the beginning of the 1990s until 2011. During this time, approximately 30,000 people, mainly from Russia and Estonia, moved to Finland. After 2011, return migration has still been possible, e.g., for Ingrian Finns (Ministry of Interior 2018: 15).

4 All interviews and narratives have been translated by Tuulikki Kurki.

\section{SOURCES}

Interview materials from 2018-2020 within the research project "A Lost Mitten and Stories: Experiences of Borders, Mobilities, and New Neighbor Relations", at the University of Eastern Finland.

\section{REFERENCES}

Alter-Muri, Simone 2019. The Body as Canvas: Motivations, Meanings, and Therapeutic Implications of Tattoos. Art Therapy: Journal of the American Art Therapy Association, Vol. 37, No. 3, pp. 139-146. https://doi.org/10.1080/07421656.201 9.1679545 .

Arnold-de Simine, Silke 2013. Mediating Memory in the Museum: Trauma, Empathy, Nostalgia. London: Palgrave Macmillan.

Balaev, Michelle 2014. Literary Trauma Theory Reconsidered. In: Michelle Balaev (ed.) Contemporary Approaches in Literary Trauma Theory. Basingstoke: Palgrave Macmillan, pp. 1-14. 
Bonansinga, Kate 2014. Curating at the Edge: Artists Respond to the U.S. / Mexico Border. Austin: University of Texas Press.

Brown, Laura S. 1991. Not Outside the Range: One Feminist Perspective on Psychic Trauma. American Imago, Vol. 48, No. 1. Psychoanalysis, Culture and Trauma, pp. 119-133. Available at https://www.jstor.org/stable/26304034?seq=1, last accessed on 20 April 2021.

Caruth, Cathy 2016 [1996]. Unclaimed Experience: Trauma, Narrative, and History. Baltimore \& London: The Johns Hopkins University Press.

De León, Jason 2013. Undocumented Migration, Use Wear, and the Materiality of Habitual Suffering in the Sonoran Desert. Journal of Material Culture, Vol. 18, No. 4, pp. 321-345. https://doi.org/10.1177\%2F1359183513496489.

Dolphijn, Rick \& Tuin, Iris van der 2012. New Materialism: Interviews \& Cartographies. Ann Arbor: Open Humanities Press.

Drechsel, Benjamin 2010. The Berlin Wall from a Visual Perspective: Comments on the Construction of a Political Media Icon. Visual Communication, Vol. 9, No. 1, pp. 3-24. http://dx.doi.org/10.1177/1470357209352947.

Dudley, Sandra H. 2010. Materialising Exile: Material Culture and Embodied Experience among Karenni Refugees in Thailand. Oxford: Berghahn.

Dudley, Sandra 2011. Feeling at Home: Producing and Consuming Things in Karenni Refugee Camps on the Thai-Burma Border. Population, Space and Place, Vol. 17, No. 6, pp. 742-755. http://dx.doi.org/10.1002/psp.639.

Facemire, Vanessa C. 2018. Understanding the Insidious Trauma of Racism: An Exploration of the Impact of Racial Socialization, Gender, and Type of Racist Experiences. Diss. (PhD Thesis). University of Akron. Available at http://rave. ohiolink.edu/etdc/view?acc_num=akron1525285448114384, last accessed on 20 April 2021.

Formenti, Laura \& West, Linden \& Horsdal, Marianne (eds.) 2014. Embodied Narratives: Connecting Stories, Bodies, Cultures and Ecologies. Odense: University Press of Southern Denmark.

Ginzburg, Carlo 1992. Clues, Myths, and the Historical Method. Baltimore: The Johns Hopkins University Press.

Hirsch, Marianne 2008. The Generation of Post-Memory. Poetics Today, Vol. 29, No. 1, pp. 103-128. https://doi.org/10.1215/03335372-2007-019.

Jäntti, Saara \& Loisa, Janne 2018. Theatre eli kotiteatteriprojekti. Teatteri toipumisen välineenä: hankkeen loppuraportti. [Theatre: A Concluding Report of the Project THEATRE - Theatre as a Tool to Recovery.] Jyväskylä: Jyväskylän yliopisto.

Jensen, Meg 2019. The Art and Science of Trauma and the Autobiographical: Negotiated Truths. London: Palgrave Macmillan. https://doi.org/10.1007/978-3-030-06106-7.

Jones, Andrew 2007. Memory and Material Culture. Cambridge: Cambridge University Press. https://doi.org/10.1017/CBO9780511619229.

Kaplan, E. Ann 2005. Trauma Culture: The Politics of Terror and Loss in Media and Literature. New Brunswick \& New Jersey \& London: Rutgers University Press.

Kidron, Carol A. 2009. Toward an Ethnography of Silence: The Lived Presence of the Past in the Everyday Life of Holocaust Trauma Survivors and Their Descendants in Israel. Current Anthropology, Vol. 50, No. 1, pp. 5-27. http:// dx.doi.org/10.1086/595623. 
Korolainen, Kari 2020. Marjatta \& Ilman Kinna. Joensuu: Kirjokansi.

Kurki, Tuulikki 2020a. Materialized Narratives of Border: Articulating the Unspeakable Through Everyday Objects. In: James W. Scott (ed.) A Research Agenda for Border Studies. Cheltenham, UK \& Northampton, MA: Edward Elgar Publishing, pp. 129-141.

Kurki, Tuulikki 2020b. Tutkimustaide. [Research Art.] Animation. Exhibition Kadonnut kinnas ja muita tarinoita. [A Lost Mitten and Other Stories.] North-Karelian Hilma Museum, Joensuu, February 6 - August 2, 2020.

Leavy, Patricia 2015. Method Meets Art. Arts-Based Research Practice. 2nd ed. New York \& London: The Guilford Press.

Maxwell, December \& Thomas, Johanna \& Thomas, Shaun A. 2020. Cathartic Ink: A Qualitative Examination of Tattoo Motivations for Survivors of Sexual Trauma. Deviant Behavior, Vol. 41, No. 3, pp. 348-365. http://dx.doi.org/10.1080/016396 25.2019.1565524.

McNiff, Shaun 1998. Art-Based Research. London \& Philadelphia: Jessica Kingsley Publishers.

Meyer, Ilan H. 1995. Minority Stress and Mental Health in Gay Men. Journal of Health and Social Behavior, Vol. 36, No. 1, pp. 38-56. http://dx.doi.org/10.2307/2137286.

Ministry of Interior 2018 = Government Policy Programme for Expatriate Finns for 20172021. Helsinki: Ministry of Interior. Available at https://julkaisut.valtioneuvosto. fi/handle/10024/160817, last accessed on 20 April 2021.

Nguyen, Vinh 2016. Nuóc/Water Oceanic Spatiality and the Vietnamese Diaspora. In: Lynda Mannik (ed.) Migration by Boat: Discourses of Trauma, Exclusion, and Survival. New York: Berghahn Books, pp. 65-80. https://doi.org/10.2307/j.ctvpj7hqz.8.

Oliveri, Federico 2016. "Where Are Our Sons?" Tunisian Families and the Repoliticization of Deadly Migration across the Mediterranean Sea. In: Lynda Mannik (ed.) Migration by Boat: Discourses of Trauma, Exclusion, and Survival. New York: Berghahn Books, pp. 154-177. https://doi.org/10.2307/j.ctvpj7hqz.13.

Parkin, David 1999. Mementoes as Transitional Objects in Human Displacement. Journal of Material Culture, Vol. 4, No. 3, pp. 303-320. http://dx.doi. org/10.1177/135918359900400304.

Povrzanović Frykman, Maja \& Humbracht, Michael 2013. Making Palpable Connections: Objects in Migrants' Transnational Lives. Ethnologica Scandinavica, Vol. 43, pp. 47-67. Available at https://www.academia.edu/6740889/, last accessed on 20 April 2021.

Ricoeur, Paul 1988. Time and Narrative, Vol. 3. Chicago: The University of Chicago Press.

Roseman, Sharon R. 2016. Children's Literature and Memory Activism: British Child Labor Migrants' Passage to Canada. In: Lynda Mannik (ed.) Migration by Boat: Discourses of Trauma, Exclusion, and Survival. New York: Berghahn Books, pp. 27-48. https://doi.org/10.2307/j.ctvpj7hqz.6.

Rothberg, Michael 2009. Multidirectional Memory: Remembering the Holocaust in the Age of Decolonization. Stanford: Stanford University Press.

Ruotsalainen, Jari 2015. Iholle kaiverrettu: Tatuoimisen kulttuurinen murros Suomessa. [Etched in Skin: The Cultural Breakthrough of Tattooing in Finland.] Joensuu: Itä-Suomen yliopisto. 
Saarelma, Päivi 2020. Pistoksissa. [Injected.] Installation. Exhibition Kadonnut kinnas ja muita tarinoita. [A Lost Mitten and Other Stories.] North-Karelian Hilma Museum, Joensuu, February 6 - August 2, 2020.

Schiffer, Michael Brian 1999. The Material Life of Human Beings: Artifacts, Behavior, and Communication. London \& New York: Routledge.

Stroinska, Magda \& Cecchetto, Vikki \& Szymanski, Kate (eds.) 2014. The Unspeakable: Narratives of Trauma. Frankfurt am Main: Peter Lang. https://doi.org/10.3726/9783-653-04423-2.

Sue, Derald Wing \& Capodilupo, Christina M. \& Torino, Gina C. \& Bucceri, Jennifer M. \& Holder, Aisha M. B. \& Nadal, Kevin L. \& Esquilin, Marta 2007. Racial Microaggressions in Everyday Life. Implications for Clinical Practice. American Psychologist, Vol. 62, No. 4, pp. 271-286. https://doi.org/10.1037/0003-066x.62.4.271.

Tanttu, Tarja 2020. Kotona. [At Home.] Installation. Exhibition Kadonnut kinnas ja muita tarinoita. [A Lost Mitten and Other Stories.] North-Karelian Hilma Museum, Joensuu, February 6 - August 2, 2020.

Tanttu, Tarja \& Kurki, Tuulikki forthcoming. Odd Man Out: Writers Addressing Othering and Exclusion in Finland. In: Tuulikki Kurki \& Tiiu Jaago \& Saija Kaskinen \& Kirsi Laurén \& Tarja Tanttu (eds.) Approaching Trauma through Clustering Concepts.

Traumaterapiakeskus $=$ Psyykinen trauma . [Psychological Trauma.] Available at https://www.traumaterapiakeskus.com/18, last accessed on 16 April 2021.

Woodward, Ian 2001. Domestic Objects and the Taste Epiphany: A Resource for Consumption Methodology. Journal of Material Culture, Vol. 6, No. 2, pp. 115-136. http://dx.doi.org/10.1177/135918350100600201.

\section{INTERVIEWS}

Interview December 20, 2018. Research interview in the research project "A Lost Mitten and Other Stories: Experiences of Borders, Mobility, and New Neighbor Relations". University of Eastern Finland. Interviewer: Tuulikki Kurki.

Interview February 15, 2019. Research interview in the research project "A Lost Mitten and Other Stories: Experiences of Borders, Mobility, and New Neighbor Relations". University of Eastern Finland. Interviewer: Tuulikki Kurki.

Interview April 27, 2019. Research interview in the research project "A Lost Mitten and Other Stories: Experiences of Borders, Mobility, and New Neighbor Relations". University of Eastern Finland. Interviewers: Tarja Tanttu and Tuulikki Kurki. Interview June 19, 2019. Research interview in the research project "A Lost Mitten and Other Stories: Experiences of Borders, Mobility, and New Neighbor Relations". University of Eastern Finland. Interviewer: Kirsi Laurén.

Tuulikki Kurki is Professor of Cultural Studies specializing in research on cultural change in the School of Humanities, University of Eastern Finland. Kurki is currently researching the themes of borders, mobility, trauma, and material objects.

tuulikki.kurki@uef.fi 